\title{
EL CARÁCTER DESINTERESADO DE LA APRECIACIÓN DE LO BELLO EN LA ESTÉTICA KANTIANA
}

\author{
JoRge Luis Cerna
}

Pontificia Universidad Católica del Perú

Resumen: El presente trabajo tiene como propósito analizar la noción de desinterés en la estética kantiana. Para ello, en la primera parte, se revisará brevemente el planteamiento estético de Shaftesbury y Schopenhauer, en los que se advierte la presencia del desinterés en relación con la apreciación de lo bello; aunque, como se verá, en sentidos muy distintos de lo propuesto por Kant. La segunda parte se centrará en la Analítica de lo bello, sobre la base de la cual se ensayarán algunas reflexiones sobre el desinterés; de esta manera se busca poner atención al desinterés propuesto por Kant no solo como un elemento negativo, sino además con una connotación abierta, positiva, que hace posible una relación distinta de la habitual con el mundo.

Palabras clave: estética, desinterés, placer, gusto, bello.

Abstract: The present paper has the purpose of analyzing the notion of disinterest in Kant's aesthetics. The first part focuses on Shaftesbury's and Schopenhauer's aesthetic approaches, wherein the presence of disinterest in relation to the appraisal of beauty is highlighted -albeit, as will be seen, in very different senses than the one proposed by Kant. The second part approaches the Analytics of beauty, around which some reflections about disinterest will be attempted in order to pay attention to disinterest as proposed by Kant, not only as a negative element, but also with an open, positive, connotation that enables a relationship with the world different than usual.

Keywords: aesthetic, disinterest, pleasure, taste, beauty. 


\section{§ 1. Introducción}

El desinterés como característica de lo estético es un aspecto que fue atendido por los pensadores del siglo XVIII. En este punto, como también en otros, Kant debe ser entendido como inserto en una tradición que motiva e inspira su reflexión, y con la cual se encuentra en permanente diálogo. La noción de desinterés posee un largo desarrollo, cuyo origen podría remontarse más allá del siglo ilustrado; sin embargo, es en este contexto, en el marco de una teoría del gusto, que se vuelve un elemento central ${ }^{66}$. En relación con esto es posible afirmar, en líneas generales, que la manera de entender el juicio de gusto o la experiencia de lo bello como desinteresado por parte de Kant se aleja de las opiniones que prevalecían en la época, y que su concepción del desinterés, además de novedosa, ha sido vista como altamente problemática ${ }^{67}$.

Para comprender la originalidad de la tesis de Kant conviene tenerla presente desde un comienzo. La primera definición de belleza que deduce Kant en la Analítica de lo bello de la Crítica de la facultad de juzgar, luego del § 5, es: "Gusto es la facultad de juzgar un objeto o un modo de representación por una complacencia o displacencia sin interés alguno. El objeto de tal complacencia se llama bello"68. De esta manera queda establecido que el juicio de gusto está marcado por un sentimiento de placer desinteresado; puesto en otras palabras, la vivencia respecto de la cual uno juzga que algo es bello, es decir, la experiencia de lo bello, o simplemente la experiencia estética, está determinada por una complacencia (Wohlgefallen) desinteresada. Hacia qué apunta está definición, cuál es su función al interior de la Analítica, y qué puede, eventualmente, implicar en la compresión y experiencia de lo bello, son algunas de las inquietudes que guiarán la siguiente exposición y sobre las cuales se intentará echar luces en su desarrollo.

66 Cf. Bozal, Valeriano, “Desinterés y esteticidad en la "Crítica del juicio»", en: José Luis Villacañas (ed.), Estudios sobre la Crítica del juicio, Madrid: Visor, 1990, p. 76.

67 Como ocurre, por ejemplo, a propósito de la relación entre interés y existencia (cf. Allison, Henry, Kant's theory of taste: a reading of the Critique of aesthetic judgment, Cambridge; New York: Cambridge University Press, 200I, p. 85).

68 Kant, Emmanuel, Crítica de la facultad de juzgar, traducción, introducción, notas e índices por Pablo Oyarzún. Caracas: Monte Ávila, 1992, § 5, BI6, p. I28. En adelante CFJ. 
En la primera parte nos serviremos del planteamiento de dos pensadores, Shaftesbury y Schopenhauer -cronológicamente un antes y un después en relación con Kant-, de modo tal que se establezca la referencia a un contexto dentro del cual se haga más notorio lo específico de la propuesta kantiana. Es pertinente señalar que la referencia a ambos autores no pretende mostrar una relación inmanente entre los planteamientos en cuestión, tampoco determinar la influencia de alguno sobre otro, ni mucho menos abarcar completamente sus reflexiones estéticas. De lo que se trata es de revisar brevemente los planteamientos estéticos mencionados en relación con la noción de desinterés para poder indicar, ahí donde sea conveniente, las particularidades y divergencias de Kant, a fin de poder ir aclarando de qué trata su concepción sobre lo bello. La segunda parte estará centrada en la exposición de los cuatro momentos que constituyen la Analítica de lo bello, con la intención de poder delimitar la noción de desinterés utilizada por Kant y, tomando como base este análisis, ensayar algunas reflexiones sobre el tema; de esta manera se busca poner atención al desinterés propuesto por Kant no solo como un elemento negativo, sino además con una connotación abierta, positiva, que hace posible una relación distinta de la habitual con el mundo.

\section{\$ 2. Consideraciones sobre el desinterés a partir de Shaftesbury y Schopenhauer}

En relación con el tema a tratar, se debe comenzar mencionando que el carácter desinteresado del juicio sobre la belleza era ya reconocido por Shafestebury antes que Kant ${ }^{69}$; sin embargo, ambos autores tendrán en mente cosas distintas. El pensamiento de Shaftesbury trata de la armonía, tanto del hombre con el hombre, como del hombre con el mundo. En función de esta armonía constitutiva, una perspectiva como la de Hobbes -un pensador impulsado por el "espíritu de la masacre"70_, cuyo planteamiento parte básicamente de una concepción egoísta de la naturaleza humana, carece de todo sentido. En Shaftesbury encontramos una afirmación de la sociabilidad como una

69 Cf. Lories, Danielle, "En torno al sentido común kantiano: sobre un antecedente y una nueva consideración”, en: Areté, IX, No. I (1997), p. II8.

70 Shaftesbury, Anthony Ashley Cooper, Conde de, Sensus communis: ensayo sobre la libertad de ingenio y humor, traducción, estudio introductorio y notas de Agustín Andreu, Valencia: PreTextos, 1995, pp. I57-I58. 
dimensión inherente a la realidad humana; es decir, se piensa en un principio de asociación y una inclinación a juntarse como lo más natural del hombre ${ }^{71}$. Además, la humanidad, en relación natural entre sí, se encuentra en armonía con el orden del mundo; de modo que nuestra existencia se basa en buscar y en "tener nuestro lugar en el ordenamiento impecable donde cada elemento contribuye a la belleza y al éxito del conjunto"72. En esta totalidad armónica se lleva a cabo la conjunción de virtud moral y belleza, en la medida en que es la persona virtuosa la que reconoce la armonía y la belleza de la que forma parte la humanidad.

Con ciertos ecos platónicos, Shaftesbury sostiene la igualdad entre bien y belleza. De esta manera puede afirmar que "la belleza más natural del mundo es la honestidad y la verdad moral"73. Una vez establecido esto, podemos ver que el desinterés que perfila Shaftesbury sobre la experiencia de lo bello está íntimamente relacionado a un fin moral. El desinterés se establece en relación a las actitudes que pervierten el carácter virtuoso: el valor, la generosidad, la templanza; se trata, entonces, de no contemplar las cosas desde la perspectiva del interés egoísta, la ventaja personal y la avaricia. En ese sentido, podría decirse que el carácter desinteresado de la apreciación de la belleza apunta a prevenir a la voluntad de malos intereses y a impulsarla hacia los buenos (en función de un imaginario ético determinado).

Este punto puede resultar útil para trazar una diferencia fundamental con el planteamiento kantiano. En la contemplación de la belleza, para Kant, "el 'desinterés' debe concernir a toda voluntad; para Shaftesbury, en cambio, sólo a una 'mala' voluntad"74. Para entender la exclusión generalizada de la voluntad conviene saber qué es lo que Kant está suponiendo por ésta. Una pista de ello puede encontrarse en la segunda sección de la Fundamentación de la metafísica de las costumbres, en la que Kant sostiene que la voluntad es "la

\footnotetext{
7 CI Cf. ibid., p. 177.

72 Lories, Danielle, op. cit., p. II0.

73 Shaftesbury, Anthony Ashley Cooper, Conde de, op. cit., p. 202.

74 Hanza, Kathia, La comunicabilidad del juicio de gusto en la Crítica del juicio de Kant, tesis de maestría en Filosofía, Lima: Pontificia Universidad Católica del Perú, Escuela de Graduados, 1992, p. 37.
} 
facultad de obrar según la representación de leyes, esto es, según principios"75; esto significa que es propio de la voluntad ponerse fines respecto de los cuales llevar a cabo sus acciones, ir tras la realización de sus fines ${ }^{76}$. Más allá de allá de considerar las diferentes determinaciones de la voluntad-obrar por inclinación para alcanzar un goce sensible, obrar en vistas al cumplimiento de un mandato racional relativo (imperativo hipotético) u obrar en vistas al cumplimiento de un mandato racional absoluto (imperativo categórico)-, lo que se propone en la Crítica de la facultad de juzgar es hacer énfasis en lo que se mantiene como rasgo inalterable en ella, esto es, el interés de la voluntad en aquello hacia lo que se dirige. De este modo, al proponer un desinterés que competa a toda la voluntad, incluso a una "buena" voluntad, podría decirse que la concepción de Kant distingue lo que en Shaftesbury estaba unido, liberando la apreciación de la belleza de su carga moral.

Pasemos ahora a Schopenhauer, quien propone una interpretación sugerente sobre la relación entre belleza y desinterés. Debido a lo amplio de su planteamiento se repasarán solo algunas nociones estéticas que resulten convenientes, en relación al Libro Tercero de El mundo como voluntad y representación. Sus ideas sobre la estética se nos presentan como una metafísica de lo bello, una aprehensión de lo bello que es desinteresada y que, como tal, trata de una liberación metafísica del mundo ${ }^{77}$. Como se verá, este desinterés resultará algo distinto del kantiano. Es importante mencionar que lo que entiende Schopenhauer por voluntad es algo más que su caracterización racionalizada, en la que comúnmente se es consciente de una finalidad o propósito; lo esencial, para Schopenhauer, es que la voluntad es impulso, movimiento primario y vital $^{78}$. Y eso que es la voluntad lo experimentamos dentro de nosotros mismos, ya que

75 Kant, Immanuel, Fundamentación de la metafísica de las costumbres, edición bilingüe y traducción de José Mardomingo, Barcelona: Ariel, 1999, p. 155.

76 En este contexto de la obra de Kant la expresión 'voluntad' refiere tanto a la razón práctica, esto es, a la facultad de actuar mediante la representación de principios, como al querer en sentido habitual. Esta ambigüedad se resolverá en Metafísica de las costumbres, donde 'voluntad' se reservará para la razón práctica, y se utilizará 'albedrío' para el querer en sentido habitual, que puede no ser racional (cf. Tugendhat, Ernst, Lecciones de ética, traducción de Luis Román Rabanaque, Barcelona: Gedisa, 1997, p. 128).

77 Cf. Philonenko, Alexis, Schopenhauer: una filosofía de la tragedia, traducción de Gemma Muñoz y Alonso López, Barcelona: Anthropos, 1989, p. 163.

78 Cf. Safranski, Rüdiger, Schopenhauer y los años salvajes de la filosofía, traducción de José Planells Puchades, Barcelona: Tusquets, 201I, p. 273. 
no somos sino voluntad. El hombre es por entero voluntad, y precisamente en el hecho de ser voluntad está conectado con el resto del mundo en sí mismo.

Esta voluntad, como impulso vital, es un querer; el hombre siempre está queriendo, $y$ "todo querer surge de la necesidad, o sea, de la carencia y, por lo tanto, de un sufrimiento"79. Este constante padecer no se acaba en la satisfacción de aquello que se desea, sino que se advierte una reproducción de las exigencias hacia el infinito; la satisfacción es efímera y uno se ve siempre preso de la voluntad, esclavo del deseo, viviendo en el constante apremio de lo se quiere y teme, de modo que no tenemos calma que dure. En palabras de Schopenhauer, "el deseo colmado cede sin demora su puesto a uno nuevo: aquél es un engaño conocido yéste uno todavía por conocer" ${ }^{80}$. La liberación de este sufrimiento, vía el goce de lo bello, propone un desinterés que abandone la estructura volitiva habitual con la que el sujeto se enfrenta al mundo; en ese sentido es compatible con Kant. Sin embargo, Schopenhauer va más allá en su formulación del estado contemplativo libre de lo bello y lo presenta como un estado de "abandono del espacio, del tiempo y del yo"81, como un punto al que nos conduce la dejación, la interrupción de la actividad ${ }^{82}$.

Tenemos en Schopenhauer una actitud estética cuya condición de placer está en el abandono de lo que se representa; mientras que el sujeto que contempla lo bello en el planteamiento kantiano es capaz de sentir placer en lo que se representa, $y$, por lo tanto, no tiene que llegar al extremo de "salir" del mundo. Además, para Kant la experiencia estética no está emparentada con una suspensión de la actividad, ni con un dejarse estar que involucre un factor aquietante de la vida, sino que, por el contrario, el estado contemplativo de lo bello -es decir, la experiencia estética- es actividad, y como tal, un estímulo de las fuerzas vitales. De esta manera, el desinterés propuesto en la estética de Kant no puede llegar a ser, de ningún modo, la mera indiferencia ${ }^{83}$.

79 Schopenhauer, Arthur, El mundo como voluntad y representación, traducción, introducción y notas de Roberto R. Aramayo, Madrid: Fondo de Cultura Económica, 2005, p. 287.

80 lbid.

8I Safranski, Rüdiger, op. cit., p. 290.

82 Cf. ibid.

83 En esta dirección apunta la observación de Heidegger al señalar que el desinterés estético de Kant comporta un esfuerzo frente al mundo, una actividad, mientras que Schopenhauer convierte equivocadamente ese desinterés en indiferencia, en un no-querer-nada-más (cf. Heidegger, Martin, Nietzsche, traducción de Juan Luis Vermal, Madrid: Destino, 2005, p. 108). 
Junto con esto resulta importante señalar otro aspecto de la estética de Schopenhauer que permite descubrir otro elemento central del planteamiento de Kant. En última instancia, vía la experiencia estética desinteresada, para Schopenhauer, el individuo "se hace libre, y se convierte en un puro sujeto de conocimiento" ${ }^{84}$. Es decir, cierto tipo de conocimiento está íntimamente ligado a la contemplación desinteresada de lo bello. Más aún, como señala Schopenhauer en los Complementos al Libro Tercero, una vez librado de la voluntad, "el conocimiento se convierte en el nítido espejo de la entidad objetiva de las cosas"85; de modo tal que se llega a obtener un conocimiento incluso de orden superior gracias al desembarazo estético de la voluntad.

De esta manera, como se menciona al comienzo del § 38 del Libro Tercero, en la contemplación de lo bello se descubre, de manera indisociable, por un lado, el conocimiento del objeto como idea platónica, no como cosa singular, sino como forma permanente, como la objetivación inmediata y adecuada de la cosa en sí que es la voluntad; por otro lado, de manera inmediata, se descubre la autoconsciencia del que conoce como puro sujeto avolitivo del conocimiento, ya no como individuo -y ambos elementos son posibles por el abandono del principio de razón que rige el conocimiento al servicio de la voluntad y que manda en la ciencia ${ }^{86}$. Antes que intentar explicar detalladamente este intrincado parágrafo, conviene solo mantener la noción de fondo que sostiene, a saber, que la experiencia estética del mundo proporciona información sobre lo que es y lo que significa la realidad ${ }^{87}$. Por el contrario, para Kant, la experiencia estética no aporta ningún conocimiento sobre el mundo o sobre uno mismo; la contemplación de lo bello no proporciona ninguna información. El proceso que realicen nuestras facultades al momento de conocer será distinto de lo que ocurra a la hora de apreciar la belleza -diferencia que, más que significar una sutileza, podría llegar a comprometer la existencia humana.

84 Ribot, Th., Schopenhauer y su filosofía, traducción de M.A., Buenos Aires: Americalee, 1946, p. 112.

85 Schopenhauer, Arthur, El mundo como voluntad y representación, II (Complementos), traducción, introducción y notas de Roberto R. Aramayo, Madrid: Fondo de Cultura Económica, 2005 , p. 356.

4287 Cf. Safranski, Rüdiger, op. cit., p. 291. 
En líneas generales, luego del contraste presentado con Shaftesbury y Schopenhauer, puede verse que la delimitación kantiana del juicio de gusto, de la facultad de juzgar lo bello, apunta a una experiencia humana distinta de la cognitiva o ética. La persecución del conocimiento o del bien se volverá algo impropio a la hora de analizar el fundamento del juicio sobre lo bello. Dicho esto, para explicar adecuadamente la posición kantiana sobre el desinterés en la experiencia estética, será necesario centrarse en los cuatro momentos que componen la Analítica de lo bello.

\section{\$ 3. Analítica de lo bello y algunas reflexiones sobre el desinterés}

En esta sección de la tercera obra crítica de Kant se busca el fundamento del juicio de gusto, de modo que se intenta sacar a la luz qué es lo que se pretende en el juicio "esto es bello". En estos parágrafos podemos encontrar el tratamiento de Kant sobre la noción de desinterés, por lo que será imprescindible revisar brevemente los cuatro momentos de la Analítica de lo bello, para luego, sobre la base de lo visto, poder extraer algunas reflexiones sobre la experiencia estética.

Es importante no perder de vista que Kant no tiene en mente una justificación del juicio de gusto en elementos empírico-psicológicos, sino que el análisis de la facultad de juzgar estética, desde el punto de vista trascendental, se propone mostrar las condiciones de posibilidad sobre las que reposa la emisión de semejante juicio. De ahí que Kant hable con frecuencia del juicio "puro" de gusto, o que tenga consideraciones formales, ausentes de contenido, a la hora de analizar el fundamento de determinación del juicio sobre lo bello. Esta perspectiva no deja de ser problemática, y en relación con lo dicho es fundamental entender que "la 'pureza' del juicio de gusto no puede, al igual que la acción conforme a la ley moral, demostrarse empíricamente. Pero la función del filósofo trascendental es mostrar sus condiciones de posibilidad. Que podamos establecer cuándo dichas condiciones se cumplen de facto es una problema distintoy, seguramente para Kant, insoluble" ${ }^{88}$. Lo cual nos indica que existen distintos planos o enfoques sobre el tratamiento del tema que no 
deben ser confundidos. Si bien es comprensible que frente a la formalidad del análisis kantiano se erija la reiterada crítica del vicio "formalista”, no por ello es del todo adecuada. Más adelante se comentará un poco más dicha objeción.

Comencemos con los cuatro momentos de la Analítica de lo bello. El primer momento del análisis, según la cualidad, nos dice que el juicio de gusto no es lógico, sino estético; y "se entiende por éste aquel cuyo fundamento de determinación no puede ser de otro modo sino subjetivo" ${ }^{89}$. En el juicio lógico se enlaza la representación al objeto por medio del entendimiento, con el fin de obtener conocimiento; mientras que en el estético se enlaza la representación al sujeto y al sentimiento de placer o displacer de éste, por medio de la imaginación en relación con el entendimiento. Podemos decir que la dirección de la representación, que es subjetiva, es lo fundamental en el juicio de gusto. Juicio que no se refiere a los objetos o a un estado de cosas del mundo, sino únicamente al sujeto y al modo como éste se siente a propósito de una representación dada. Cabe señalar que antes de que Kant mencione lo determinante del desinterés en el sentimiento con el cual el sujeto es afectado en la experiencia estética, se establece que dicho sentimiento es un "sentimiento vital" estética, para Kant, está vinculada a un estado de vitalidad y a un impulso de la actividad.

Cuando el sujeto dice que algo es bello lo que realmente está diciendo es que experimenta un sentimiento de placer. Ahora bien, dicho sentimiento de placer suscitado a propósito de una representación, para que se trate propiamente de lo bello, deberá ser desinteresado. En palabras de Kant, "interés se denomina a la complacencia que ligamos a la representación de la existencia de un objeto"91. De modo que cuando se juzga que algo es bello uno debe ser indiferente a la existencia de tal cosa; "aquello en que yo dependa de la existencia del objeto" 92 no tiene relevancia alguna al momento de decir de éste que es bello.

89 Kant, Emmanuel, CFJ, § I, B4, p. I2I.

90 Ibid., § I, B4, p. 122.

9I Ibid., § 2, B5, p. 122.

92 Ibid., § 2, B6, pp. I22-123. 
En esta definición del interés -complacencia ligada a la representación de la existencia de algo- puede advertirse que el término representación (Vorstellung) se usa de un modo un tanto ambiguo ${ }^{93}$. En sentido amplio, Vorstellung es simplemente toda cosa de la que uno es consciente; al ser consciente de la existencia de algo, el interés está en sentir placer en la existencia de ese algo. Pero rápidamente podemos caer en la cuenta de que el interés no puede ser reducido a una complacencia que ocurre necesariamente al experimentar algo existente. Si en relación con esto tomamos la representación más como un estado mental, emparentado con una actividad conceptual, tenemos un interés que se dirige hacia o se relaciona con un objeto que puede no existir actualmente ${ }^{94}$. De esta manera se hace comprensible que no solo lo agradable, "lo que place a los sentidos en la sensación" 95 , sea interesado, sino que lo bueno, "lo que place, por medio de la razón, por el mero concepto" 96 , también lo sea.

En lo agradable la sensación subjetiva que se obtiene supone un interés. En este caso el estado de complacencia se relaciona con la existencia de su objeto en la medida en que es afectado por éste; a lo agradable no solo le dedico una mera aprobación, sino que me produce una inclinación ${ }^{97}$. Por otro lado, en lo bueno está contenido el concepto de un fin, de modo que, en última instancia, tanto lo bueno para algo (lo útil) como lo bueno en sí mismo (lo moral) supone un interés. Se trata de "una complacencia en el existir de un objeto o de una acción"98; una existencia que, aunque no se dé actualmente, compromete a la voluntad en su cumplimiento. El sujeto se encuentra tras la persecución racional de un fin, es decir, desea la realización de aquello que toma como bueno, ya sea bueno para algo, y tenga un interés en su utilidad como medio para algún agrado, o ya sea lo bueno moral, "que conlleva el más elevado interés" 99 .

93 Cf. Crawford, Donald, Kant's aesthetic theory, Madison: University of Wisconsin Press, 1974, p. 39.

94 Cf. ibid., pp. 39-40.

95 Kant, Emmanuel, CFJ, § 3, B7, p. 123.

96 Ibid., § 4, BI0, p. 124.

97 Cf. ibid., § 3, BI0, p. 124.

98 Ibid., § 4, BI0, p. 125.

99 Ibid., § 4, B।4, p. 126. 
La complacencia en lo agradabley en lo bueno, ambas interesadas, saca a relucir un aspecto parcial del hombre, la sensibilidad o la razón, respectivamente. Mientras que la contemplación placentera de lo bello solo es posible para el ser humano considerado cabalmente; vale la belleza "sólo para los hombres, es decir, para seres de naturaleza animal y, sin embargo, racionales"100. Y en relación con esta particular experiencia propia del hombre debe quedar establecido que el gusto por lo bello "es una complacencia desinteresada y libre, pues ningún interés, ni el de los sentidos, ni el de la razón, fuerza la aprobación”|01. Es en ese sentido que el juicio de gusto es libre. Libertad entendida no en los términos de la libertad de la razón práctica en relación al mandato moral, sino como la posibilidad de ser libre respecto de cierta parcialidad, libre de la unilateralidad de relacionarse con los objetos en términos de fines. De ahí que Kant diga que la complacencia en lo bello no consiste en la inclinación o el respeto, pues ambos pueden mostrar la fuerza que ejercen sobre el sujeto, sino que es al modo del favor (Gunst) ${ }^{102}$ : complacencia libre de ajustarse a fines. De esta manera, el primer momento del análisis del juicio de gusto saca a la luz que el juicio sobre lo bello es subjetivo, trata de cómo se siente el sujeto, y dicho sentir es una complacencia desinteresada.

El segundo momento del análisis, según la cantidad, nos dice que el juicio de gusto es universal sin por ello fundarse en conceptos, es decir, en determinaciones objetivas que lo conviertan en un juicio lógico. Para establecer esta universalidad se partirá de lo dicho en el momento anterior: bello es lo juzgado por una complacencia desinteresada; luego, "aquello en lo cual se tiene una complacencia de la que se es consciente que carece de todo interés, no puede ser juzgado de otra manera que como si debiese contener un fundamento de complacencia para todos"103. En otras palabras, dado que la contemplación placentera de lo bello no se funda en una condición privada -ya que es desinteresada-, entonces debe considerársela como fundada en algo que puede suponerse en cualquier otro. Esta pretensión de universalidad es semejante a la del juicio lógico, en tanto se busca validez ante todos, pero al tratarse de

100 Ibid., § 5, BI5, p. 127.

I0I Ibid.

102 Cf. ibid.

$46 \quad 103$ lbid., § 6, BI7, p. 128. 
un juicio estético la universalidad no puede ser objetiva, no puede reposar en conceptos, sino que ha de ser subjetiva.

El juicio de gusto, aunque subjetivo, no puede ser de ninguna manera privado. Kant retoma la distinción entre lo agradable (privado) y lo bello (público), para señalar que quien juzga que algo es bello "no juzga solo para sí, sino para todos"104; de modo que el análisis kantiano se apoya sobre la base de que, a diferencia de lo que ocurre en nuestros juicios sobre lo agradable, que son privados y hasta gustamos de que así sea, a nuestros juicios sobre lo bello les atribuimos universalidad; en el juicio acerca de la belleza de algo se aspira al asentimiento de todos -e incluso se puede decir que se exige tal coincidencia. Es por ello que en el juicio de gusto se le atribuye la complacencia a cada cual (jedermann); pero "sólo se postula la posibilidad de un juicio estético que pueda ser considerado a la vez como válido para todos. El mismo juicio de gusto no postula el acuerdo de todos"105. Establecer la concordancia de facto en los casos particulares solo puede hacerse en un juicio lógico debido a su universalidad objetiva basada en conceptos; en cambio, en el caso del juicio de gusto, la universalidad subjetiva solo cuenta con el sentimiento de placer del sujeto.

Dado que el sentimiento de placer del sujeto es un aspecto central del juicio de gusto, Kant se propone aclarar si éste antecede al enjuiciamiento o viceversa. Si el placer fuera lo primero, el juicio se limitaría a comunicar dicho sentimiento de placer, y así el ámbito de lo privado se superpondría a la pretendida universalidad. Es por ello que, en relación al orden de fundamentación, el placer debe ser entendido como secundario, una consecuencia en relación con el juicio de gusto. Dice Kant que "es la universal aptitud de comunicación del estado del ánimo en la representación dada, la que, como condición subjetiva del juicio de gusto, debe estar en el fundamento de éste y tener como consecuencia el placer por el objeto"106. El fundamento de determinación del juicio de gusto, entonces, como universal subjetivo, no puede ser otro que "el estado del ánimo que se encuentra en la relación de las fuerzas

104 Ibid., § 7, B20, p. 129.

105 Ibid., § 8, B26, p. 132.

106 Ibid., § 9, B27, p. 133. 
representacionales entre sí, en cuanto que ellas refieren una representación dada al conocimiento en general"|07.

La relación a la que alude Kant es la del libre juego de las facultades de conocimiento, imaginación y entendimiento, en la medida en que éstas concuerdan entre sí como se requiere para llegar a un conocimiento, aunque no se llegue a ninguno. Participa la imaginación, para la composición de lo múltiple de la intuición, y también el entendimiento, para la unidad del concepto que unifica las representaciones; sin embargo, la relación de ambas facultades no es la que se da en los juicios determinantes, en los que la relación tiene una dirección unilateral, y el entendimiento subsume lo que presenta la imaginación bajo las categorías con vistas a un conocimiento determinado. En el juicio estético, como juicio reflexionante, las facultades se relacionan de manera armónica, sin jerarquías, se estimulan mutuamente y se alientan a permanecer activas, de modo que "la imaginación, en su libertad, despierta al entendimiento y éste, sin conceptos, pone a aquélla en un juego regular"108. Libertad y regularidad en relación con la actividad en la que se ponen las facultades de conocer humanas, es ese el estado de vivificación del ánimo en el que se encuentra el sujeto frente a lo que juzga como bello, y dicho estado es lo que se traduce como un sentimiento de placer; es decir, el placer se sostiene en el libre juego de las facultades de conocimiento, nunca en condiciones privadas. En relación con semejante placer es que el juicio de gusto postula la comunicabilidad universal, de modo que el placer pueda hacerse extensivo a todos sin la determinación de conceptos, únicamente basándose en un peculiar uso de las facultades que todos poseen.

El tercer momento del análisis, según la relación de los fines, nos dice que en el juicio de gusto el modo de representación de algo, la manera como se relacionan las facultades de conocimiento, se da bajo la forma de la conformidad a fin, puesto que no se puede identificar un fin determinado. En este momento se presta atención a lo formal de la relación entre imaginación y entendimiento, desprovisto del contenido sensible o conceptual que pueda estar presente, y se observa en la forma de esa relación una conformidad a fin.

107 Ibid., § 9, B28, pp. 133-134. 
El juego de las facultades en cuestión se explica como una conformidad a fin, en tanto se encuentran en armonía o concordancia. En esta consideración formal, sin tomar en cuenta el contenido, no se puede plantear la representación de un fin objetivo como el fundamento del juicio de gusto; ni tampoco, por ello, será lícito el establecimiento de un fin subjetivo con un rol fundamental. El sentimiento de placer que experimenta el sujeto no es el motivo del juicio de gusto. La experiencia estética, el estado de ánimo del libre juego de las fuerzas representacionales a propósito de una representación, no tiene por fin la producción del sentimiento de placer; dicho de un modo más exacto, no tiene ningún fin. Kant advierte que "todo fin, cuando es considerado como fundamento de la complacencia, conlleva siempre un interés como fundamento de determinación del juicio sobre el objeto del placer"109. Lo que no debe perderse de vista, en relación con esto, es que el sentimiento de placer no es algo distinto de la peculiar actividad en la que se ponen las facultades de conocimiento, la imaginación y el entendimiento; es la actividad de las facultades la que se siente como placer, y es en ese sentido que la experiencia estética, desprovista de cualquier fin que quiera ser puesta en ella, es por sí misma placentera.

Se trata de un estado de contemplación de la belleza, porque en él no se presta atención a fin o interés alguno, no se tiene ningún "para”. En relación con esto Kant advierte que, "no obstante, tiene en sí una causalidad, a saber, aquélla dirigida a conservar sin propósito ulterior el estado de la representación y la actividad de las facultades de conocimiento" ${ }^{\prime \prime 0}$. Continuar en la contemplación de lo bello, en la constante actividad armónica de las facultades, es la conformidad a fin admisible en el estado de apreciación de lo bello, sin que por ello el mantener el estado estético se busque con otra intención que la de mantenerse en dicho estado. "Nos quedamos en la contemplación de lo bello, porque esta contemplación se refuerza y reproduce a sí misma" "I. De esta manera, la contemplación no tiene alguna otra intención que ella misma, no tiene como meta ningún conocimiento objetivo en el que agotarse o detenerse; no va tras algún contenido, no es el medio para un fin. Cualquier contenido, concepto o sensación, que quiera ser puesto como el fin que determina el

109 Ibid., § II, B34, p. 137.

II0 Ibid., § 12, B37, pp. 138-139.

III Ibid., § I2, B37, p. 139. 
juicio de gusto terminaría por desvirtuarlo. Es por ello que la forma de conformidad a fin que se reconoce en el juicio de gusto es sin fin alguno.

El cuarto momento de juicio de gusto, según la modalidad, nos dice que el sentimiento de placer en el juicio de gusto es necesario. En contraste con lo agradable, donde lo que se comunica es un sentimiento privado y no hay ninguna relación necesaria con el placer, en lo bello sí se atribuye una "relación necesaria con la complacencia"|'2. Inmediatamente Kant advierte que no se trata de una necesidad teórica objetiva o práctica, a partir de la cual la relación entre lo bello y el placer se fundaría en conceptos que la predeterminen. No es posible establecer una necesidad apodíctica que enlace la representación que juzgamos como bella y el placer de una manera lógicamente necesaria; en otras palabras, podría decirse -siguiendo el planteamiento kantiano-que la apreciación de la belleza no puede estar predeterminada, sino que es una experiencia que debe hacer cada cual.

La necesidad que se atribuye al juicio estético es, de acuerdo con Kant, de otro tipo, y, de acuerdo con él, solo puede ser llamada necesidad ejemplar. Esto significa que se trata "de la necesidad del asentimiento de todos a un juicio que es considerado como ejemplo de una regla universal que no puede ser aducida"|'3 . La necesidad de placer en los juicios estéticos no puede derivarse de conceptos determinados, ni puede ser inferida de la universalidad de la experiencia; además, el juicio de gusto solo puede ser el caso de una regla que no puede ser formulada, ya que si se fijara una regla determinada para el asentimiento de todos se estaría haciendo del juicio estético algo objetivo. Sin embargo, si bien se carece de un principio objetivo que provea necesidad incondicionada, no por eso debe caerse en la carencia total de principio y la anulación de toda necesidad posible, es decir, en la arbitrariedad de lo bello; los juicios estéticos "deben tener, por consiguiente, un principio subjetivo que determine, solo por sentimiento y no por concepto, y sin embargo, con validez universal, lo que plazca o displazca"|l4. Este principio subjetivo, según Kant, es el sentido común (sensus communis), considerado como la facultad

112 lbid., § 18, B62, p. I5I.

II3 Ibid., § I8, B62-63, p. 152.

II4 Ibid., § 20, B64, p. 152. 
de juzgar en base al sentimiento que proviene del libre juego de las facultades de conocimiento.

El sentido común será el principio subjetivo que haga posible comunicar universalmente nuestro estado, ya que "la universal comunicabilidad de un sentimiento supone un sentido común" "15. Éste sustenta y explica la posibilidad del asentimiento de cada cual. "En todos los juicios a través de los que declaramos que algo es bello, no permitimos a nadie ser de otra opinión; y sin embargo, no fundamentamos nuestro juicio en conceptos, sino sólo en nuestro sentimiento, que ponemos por fundamento, pues, no como sentimiento privado, sino como uno común" 116 . El sentido común es la facultad que juzga en base al sentimiento de placer desinteresado, sin alusión a condiciones subjetivas privadas, de manera que en el juicio de gusto se atribuye dicho placer a toda la esfera de los que juzgan ${ }^{117}$. Que tal sentido común sea un principio constitutivo de la experiencia o un principio regulativo que la razón nos impone, y lo que esto pueda implicar, son cuestiones que el propio Kant deja abiertas hacia el final de la Analítica de lo bello y que, para el propósito de este artículo, basta con mencionarlas.

Una vez recorridos los cuatro momentos de la Analítica de lo bello podemos detenernos a presentar algunas breves reflexiones sobre la caracterización kantiana de la experiencia estética, es decir, sobre la apreciación de la belleza a la luz de las condiciones que se muestran del análisis del juicio de gusto, en relación con el desinterés. La Analítica de lo bello, como hemos visto, consta de distintos momentos, que se sirven de categorías del entendimiento, y que permiten una aproximación variada, desde perspectivas diferentes, sobre un mismo asunto. En ese sentido, conscientes de la unidad del tema, es posible leer el desinterés como un elemento relacionado a la totalidad de la experiencia estética. De esta manera, podría decirse que el análisis según la

\footnotetext{
II5 Ibid., § 2I, B66, p. 153.

116 Ibid., § 22, B66-67, p. 154.

II7 "Por sensus communis hay que entender, no obstante, la idea de un sentido común a todos, esto es, de una facultad de juzgar que en su reflexión tiene en cuenta, en pensamiento (a priori), el modo representacional de cada uno de los demás, para atener su juicio, por así decirlo, a la entera razón humana y huir así de la ilusión que, nacida de condiciones subjetivas privadas que pudiesen fácilmente ser tenidas por objetivas, tendría una desventajosa influencia sobre el juicio" (ibid., § 40, BI57, p. 204).
} 
cualidad, en donde se establece la función determinante del desinterés en la complacencia en lo bello, es el momento inaugural, y, como tal, proporciona el criterio básico sobre el cual se hacen comprensibles los rasgos principales del juicio de gusto y la contemplación de lo bello.

Sin embargo, no debe perderse de vista que, si bien el desinterés es un criterio central del juicio, no por ello es, en última instancia, su fundamento; las condiciones de derecho a cumplir reconocidas como legítimas para hablar de juicios de gusto, entre las cuales se puede destacar el desinterés, se apoyan en el sentido común (sensus communis) como el fundamento sobre el que reposa la emisión de todo juicio de gusto. El desinterés proporciona una base para señalar aquello que se pretende, a la vez que le da sentido a dicha pretensión, pero el juicio de gusto no sería posible sin el sentido común entendido como la facultad de juzgar subjetiva basada en el sentimiento.

En todo caso, en relación con nuestro asunto, lo fundamental es comprender que el desinterés para Kant, como ya se mencionó en relación con Schopenhauer, no es la mera indiferencia. El estado de contemplación desinteresada de lo bello se siente como placentero a propósito de una representación dada, en la medida en que las facultades de conocimiento del sujeto se encuentran en libre juego. Semejante estado de ninguna manera comporta apatía, pasividad, ni implica una desconexión del sujeto con su vida. El sujeto siente nada menos que placer respecto de lo bello, y dicho estado de contemplación desinteresada implica actividad, vitalidad, la vivificación del estado de ánimo. En relación con lo observado, podríamos mencionar a Nietzsche como un punto más próximo a este aspecto de la experiencia estética, ya que, mientras que "para Schopenhauer, el arte es un 'calmante' de la vida, Nietzsche ve en él el 'estimulante' de la vida"|l8. En ese sentido específico, en relación a la apreciación de la belleza y el "sentimiento vital" que ello implica, podría decirse que Nietzsche ${ }^{119}$ está más cerca de Kant que Schopenhauer.

II8 Jähnig, Dieter, Historia del Mundo: Historia del Arte, México D.F.: Fondo de Cultura Económica, 1982, p. 179.

II9 El impulso estético de la vida puede ser visto en Nietzsche desde la contraposición entre arte y conocimiento conceptual: "El arte es más poderoso que el conocimiento, porque él quiere la vida, mientras que el conocimiento alcanza como última meta sólo -- la aniquilación” (Nietzsche, Friedrich, "Sobre el pathos de la verdad", en: Obras completas, I, Madrid: Tecnos, 20II, p. 548); "el ser humano despierto tan solo tiene claro que está despierto gracias al rígido 
Es común considerar el desinterés desde un punto de vista negativo, es decir, tomando en cuenta aquello que excluye. De este modo, el desinterés apunta a que "toda una serie de elementos no tiene derecho de ciudadanía en el pronunciamiento del juicio de gusto -los fines utilitarios de todo género, el seguimiento de fines exteriores a la experiencia estética y a su objeto, las referencias a la idiosincrasia del sujeto que juzga, a su situación particular, a su afectividad personal, sus deseos y emociones privadas" 120 . Todas estas cosas deben ser excluidas. En otras palabras, desde este punto de vista negativo, el desinterés es como un filtro que separa lo que no debe ser mezclado. Pero el desinterés también puede ser visto desde un punto de vista positivo, no solo desde lo que niega, sino desde una perspectiva de "atención ante lo que se da en la experiencia estética"|21. En este enfoque positivo pueden separarse dos sentidos, uno de "autorreferencia", en el que se atiende a lo que ocurre en el sujeto, y otro de apertura a lo otro de sí, en el que se atiende al abrirse del sujeto al mundo -aunque se trata solo de una distinción metodológica, ya que, sin importar dónde se ponga el acento, en última instancia, ambos sentidos están unidos de principio a fin.

En términos de lo que ocurre en el sujeto, se podría decir que en la experiencia estética se hace posible una vivencia que no tiene nada que ver con el conocimiento, ni de uno mismo ni del mundo. Cabe, entonces, la posibilidad de librarse de cierta obsesión teórica que ha definido al hombre desde la antigüedad. Además se hace posible una experiencia en la que el sujeto no busca superarse; no se persigue una realización moral de ningún tipo, ni ningún tipo de realización. En la experiencia estética se descubre, en última instancia, la posibilidad de ser libre para ser como se es, sin verse circunscrito a las necesidades de ser un sujeto cognoscente o moral. Lo cual se relaciona, indefectiblemente, con el modo en que el sujeto está y se relaciona con el mundo; la experiencia estética abre la posibilidad de una forma de estar en

\footnotetext{
y regular tejido conceptual (...), el arte desgarra ese tejido conceptual” (Nietzsche, Friedrich, "Sobre verdad y mentira en sentido extramoral", en: op. cit., p. 618). Dejando de lado los motivos específicos de las reflexiones de Nietzsche en estos escritos, puede establecerse un vínculo con Kant, en la medida en que para ambos lo estético trae a cuenta una experiencia fundamentalmente diferenciada de la mera captación lógico-conceptual del mundo.

120 Lories, Danielle, op. cit., p. 118.

I2I Quintana, Laura, Gusto y comunicabilidad en la estética de Kant, Bogotá: Universidad de los Andes, 2008, p. 268.
} 
el mundo distinta a la de conocer o de cumplir mandatos morales. En este momento el desinterés hace posible una relación distinta con el mundo, los objetos y la naturaleza. En relación con el desinterés en la experiencia estética kantiana, interpreta Heidegger que para encontrar algo bello, "tenemos que dejar en libertad lo que nos sale al encuentro como tal en lo que él mismo es, tenemos que dejarle y concederle lo que le pertenece y lo que nos aporta"122. En esta dirección, la del favor (Gunst), la contemplación desinteresada de lo bello establece una relación con las cosas en la que el sujeto puede aceptar lo que se presenta tal y como es, libre de una lógica instrumental -típicamente moderna- que busca apropiarse y utilizar todo lo que se le presenta; se trata de una experiencia que nos lleva a desconectarnos de cierta mentalidad cotidiana en la que nos relacionamos unilateralmente con las cosas, y en la que se nos permite aproximarnos al mundo de manera, tal vez, más íntima -"precisamente gracias al «sin interés» entra en juego la relación esencial con el objeto mismo"|23.

Finalmente, prestando atención a esto último, sobre la posible íntima relación con el objeto, podemos intentar comentar un aspecto más sobre la experiencia estética que nos advierta contra la recurrente crítica al "formalismo" kantiano. Debido al análisis formal y subjetivo que realiza Kant, se ha interpretado su estética como carente de todo objeto y contenido. En relación con los objetos bellos, según Hegel, "Kant sólo los considera desde el punto de vista de la reflexión que los enjuicia subjetivamente”|24. En una línea similar, Adorno sostiene que en la estética kantiana se lleva a cabo el vaciamiento "de cualquier contenido y en su lugar se coloca algo tan puramente formal como la complacencia"|25. Frente a esto es posible señalar que, aunque el contenido -esto es, el objeto- no sea el fundamento de determinación de la experiencia estética, eso no significa su total exclusión.

Que Kant realice un análisis formal, "no significa que el sujeto no se relacione de ninguna manera con el objeto, ni mucho menos que éste sea un

122 Heidegger, Martin, op. cit., p. 109.

123 Ibid.

124 Hegel, G. W. F., Lecciones de estética, traducción de Raul Gabás, Barcelona: Ediciones 62, 1989, p. 45.

I25 Adorno, Theodor, Teoría estética, traducción de Fernando Riaza, Barcelona: Orbis, 1983, p. 23. 
mero pretexto para que lo bello sea extraído del sujeto mismo"126. En ese sentido, la experiencia estética parte de la representación de un objeto, se da a propósito de algo distinto del sujeto mismo y eso la hace posible. "La 'complacencia' sólo puede ser complacencia de algo, es decir, en donde el objeto es la causa de un sentimiento" 27 ; sentimiento que el sujeto experimenta como placentero en el juego de sus facultades cognitivas. En relación con lo cual parece un poco exagerado hablar de un "hedonismo castrado"128 en la estética de Kant, ya que el objeto (Gegenstand) sí participa de la experiencia estética. Como menciona Laura Quintana, señalando una observación de Taminiaux, "parecería que el juicio más radicalmente subjetivo, aquel que no busca conocer ni determinar nada en el objeto, por paradójico que parezca, sería aquel que estaría más abierto al modo de ser de su objeto"129. Lo cual nos permite observar que el problema del interés no es tanto la participación de un objeto como la predisposición del sujeto interesado a representarse tal objeto con vistas a cierto fin. El desinterés apunta a excluir un tipo de consideración particular e interesada de la existencia de las cosas, pero no por eso excluye la existencia de todo objeto. En última instancia, podría decirse que a la experiencia estética desinteresada, de alguna manera, sí le interesa la existencia del objeto, en la medida en que éste hace posible la experiencia estética, aunque no por eso la determina.

I26 Cañas, Roberto, "El sujeto en la estética kantiana", en: Revista de Filosofía (Universidad de Costa Rica), XXXIV, No. 83-84 (1996), p. 287.

127 Ibid.

128 Adorno, Theodor, op. cit., p. 23.

129 Quintana, Laura, op. cit., p. 272. 